\title{
The effect of stimulus characteristics on immediate and delayed transposition
}

\author{
KENNETH A. BLICK ${ }^{1}$ and JOHN I. MCCLURKIN, III, ${ }^{2}$ \\ Randolph-Macon College, Ashland, Virginia
}

Following training on a visual discrimination problem, transposition was examined immediately and after a four-week delay. The number of relational responses did not increase significantly over the delay period. An additional stimulus characteristic during training was used to predict the incidence of relational and absolute responses during transposition.

The phenomenon of transposition occurs when the relationship between several stimuli is learned, and once learned, is applicable among new stimuli along the same physical dimension. There has been much controversy about whether the transposed knowledge is based upon the absolute values of the stimuli or upon some relationship between them. There has also been some question as to the effect of a temporal delay between training and testing upon the type of response (i.e., either absolute or relational) given on a test for transposition.

According to Hall (1966, p. 459), “. . the examination of transposition learning appears to rest upon an analysis of the conditions which determine whether the effective stimulus shall consist of the absolute properties or a relationship between the discriminanda." Hall goes further and indicates that although it seems apparent that a $S$ may learn to respond on the basis of both absolute and relational qualities of a stimulus, it would be well to analyze the conditions which facilitate the dominance of one of these qualities over the other. The present experiment was designed to show the effect of a temporal delay much longer than has previously been used (four weeks) on the amount of transposition, and also to determine some of the possible conditions which account for absolute or relational responding.

\section{METHOD}

Sixty-four male undergraduates in two introductory psychology classes at Randolph-Macon College served as Ss. One class contained 34 Ss and the other had 30 Ss. The visual discrimination problems were presented to the intact groups by means of a $35 \mathrm{~mm}$ slide projector. The Ss were provided with answer sheets which contained brief instructions and spaces in which to indicate their responses. The two groups differed only in the amount of time between training and testing for transposition. One group $(\mathrm{N}=34)$ was trained and tested immediately for transposition. The second group $(\mathrm{N}=30)$ was tested for transposition after a four-week delay. In order to prevent any interaction between $S$ s in the two groups, the training sessions occurred on different days while the test for transposition occurred on the same day.

The training phase consisted of 12 visual discrimination problems. Each slide contained a pair of geometric figures (squares, circles, or triangles) of different colors (red, yellow, blue, or green). In each pair the figures were always homogeneous, i.e., circles were paired with circles, squares with squares, etc. The areas of the figures were in the size ratio of $3: 5: 7$.

The 12 training trials contained figures of size ratio 3:5 with Size 5 as the correct figure. In addition, Figure 5 was always the color red on the 12 training trials. During training the Ss were told: "You are going to see a series of slides consisting of a pair of geometric figures. Only one figure of each pair is correct on the basis of some principle, and your talk is to learn to discriminate the correct figure on the basis of this principle." A training trial lasted 15 sec. After a 5 -sec exposure the Ss were given $5 \mathrm{sec}$ to indicate on the answer sheet their choice of the correct figure. Following their response was E's announcement of the correct figure.

The test phase consisted of 14 slides presented at a 10-sec rate, and the test instructions read: "On the next series of slides you will not be told which figure is correct." The first six test slides were used as a check to see if the Ss had learned the primary discrimination, i.e., the large, red figure was correct. These six trials contained figures in the size ratio $3: 5$, and none of the Ss responded incorrectly to any of these slides.

The last eight slides of the test series showed figures of size ratio $5: 7$ at the $10-\mathrm{sec}$ rate with no answers furnished. During these eight test trials the larger figure (7) was red on three trials, the smaller figure (5) was red on three trials, and neither figure was red on two trials. During the entire experiment the presentation of the slides was randomized so that the position of the larger figure was changed from left to right, and the color of the smaller figure was assigned on a random basis.

\section{RESULTS}

The percentage of relational responses given by the Immediate and four-week Delay groups during the last eight test trials are presented in Table 1. The column labeled Small Red indicates that the smaller figure (Size 5) was red, Large Red means that the large figure (Size 7) was red, and Neither Red indicates that neither 5 nor 7 was red.

A total of $272(34 \times 8)$ responses occurred in the Immediate group and 240 responses $(30 \times 8)$ in the Four-Week Delay group. In the Immediate group, the test responses were arranged such that there were 68 (34 Ss by 2 trials) possible responses when neither figure was red. So the result of $91 \%$ for the Immediate group under Neither Red means that $91 \%$ of the test responses were to the larger non-red figure (a relational response).

Overall, the expected increase in the percentage of relational responses over the delay interval failed to appear as indicated in the Total column in Table 1. The difference between $73 \%$ for Immediate and $77 \%$ for 4 -Week Delay failed to reach statistical significance $(z=.95, p>.01)$. The difference between Immediate and 4-Week Delay was not significant on Large Red trials $(z=1.09, p>.01)$ and Neither Red trials $(z=.81, p>.01)$; however, there was a significant increase in relational responses on Small Red trials $(z=2.40, p<.01)$.

The major finding concerning the percentage of relational responses as a function of the stimulus characteristic of color during the test trials was that the Small Red condition always produced significantly fewer relational responses. For the immediate group the Small Red value of $52 \%$ was significantly different $(z=5.81, p<.01)$ from the Large Red value of $97 \%$. The difference was also significant for the 4-Week Delay group $(z=4.10, p<.01)$. In addition, none of the differences between Large Red and Neither Red were significant.

Table 1

Percentage of Relational Responses Given During Transposition Trials by Immediate and 4-Week Delay Groups

Stimulus Characteristic During Transposition

\begin{tabular}{lcccc} 
Group & Small Red & Large Red & Neither Red & Total \\
\hline Immediate & 52 & 97 & 91 & 73 \\
4-Week Delay & 67 & 90 & 83 & 77 \\
Total & 59 & 94 & 87 & \\
\hline
\end{tabular}




\section{DISCUSSION}

The overall null result concerning the temporal delay factor does not agree with other experiments. For example, Kohler (1929) concluded that a relationship between facts is more persistently remembered than an individual fact. Thompson (1955) found more relational responses with rats after $24 \mathrm{~h}$ than when tested immediately, and Spence (1942), using chimps, found that a 24-h delay produced more relational responses. Stevenson \& Langford (1957) also found that in young children transposition was greater after a delay of $24 \mathrm{~h}$.

Presumably, the trend for transposition responses to increase positively as a function of a delay interval is due to the fact that long delays make it more difficult for $S$ to discriminate the absolute properties of the training and test stimuli. In the present experiment there was a significant rise in relational responses from $52 \%$ to $67 \%$ only when the small figure was red during the test phase. Apparently, the additional stimulus characteristic of color complicated the problem and forced $S$ to rely on the more easily remembered relationship between the two stimuli.
Quite possibly the major finding of the present experiment concerned the role of the additional stimulus characteristic of color. The Ss learned that the large, red figure was correct during the training phase; however, they gave significantly fewer relational responses on test trials when the smaller stimulus was red. With the present procedure it becomes possible to predict the incidence of relational and absolute responding and to provide some insight into variables controlling either of these responses.

$$
\text { REFERENCES }
$$

HALL, J. F. The psychology of learning. Philadelphia: J. B. Lippincott, 1966.

KOHLER, W. Gestalt psychology. New York: Horace Liveright, 1929.

SPENCE, $K$. W. The basis of solution by chimpanzees of the intermediate size problem. Journal of Experimental Psychology, 1942, 31, 257-271.

STEVENSON, H. W., \& LANGFORD, T. Time as a variable in transposition by children. Child Development, 1957, 28, 365-370.

THOMPSON, $R$. Transposition in the white rat as a function of stimulus comparison. Journal of Experimental Psychology, 1955, 50, 185-190. NOTES

1. Now at the University of Richmond. 2. Now at Michigan State University. 